\title{
Prevalence of neural tube defects and estimation of cases averted in the post-fortification period in Argentina
}

\author{
María P. Bidondo, M.D. ${ }^{a}$, Rosa Liascovich, M.D. ${ }^{a}$, Pablo Barbero, M.D. ${ }^{a}$, \\ and Boris Groisman, M.D. ${ }^{a}$
}

\begin{abstract}
Periconceptional intake of folic acid has demonstrated to be effective to reduce the frequency of neural tube defects, and food fortification has been one of the strategies implemented to increase it. An update is herein presented on the reduced prevalence of neural tube defect cases in the post-fortification period in Argentina and an estimation of cases averted in the 2005-2013 period as a result of this intervention. When comparing the prevalence observed in the post-fortification period to that reported in the pre-fortification period, anencephaly and encephalocele decreased by $66 \%$, and spina bifida, by $47 \%$, which were significant reductions. The estimated number of cases averted was higher for anencephaly, followed by spina bifida; encephalocele showed the lowest number of cases averted given that the prevalence of this defect was smaller. The decrease observed in the prevalence supports findings from previous studies on the impact of fortification.

Key words: neural tube defects, spina bifida, food fortification, folic acid, prevalence, Argentina.
\end{abstract}

the activities conducted by the National

Registry of Congenital

Anomalies, member of the National Center for Genetic Medicine, and component of the Program for Uncommon Diseases and Congenital Anomalies established by the Ministry of Health. This study has been partially funded by the National Agency of Scientific and Technological Promotion through the 2011 Scientific and Technological Research Project of the National Administration of Health Institutes and Labs (PICTO-ANLIS) no. 0147, and the Plan NACER-SUMAR.

Conflict of Interest: None.

Received: 3-19-2015 Accepted: 6-24-2015 http://dx.doi.org/10.5546/aap.2015.eng.498

\section{INTRODUCTION}

Neural tube defects (NTDs) are major structural congenital anomalies (CAs) of the brain and the spinal cord. NTDs originate early during pregnancy as a result of a defective closure of the neural tube, which may result in death or disability. The most common NTDs are anencephaly and spina bifida. Fetuses with anencephaly are stillborn or die in the first few hours after birth. Newborn infants with spina bifida and encephalocele require specific medical and surgical care. $^{1}$

Periconceptional intake of folic acid (FA) has demonstrated its effectiveness to reduce the occurrence of NTDs, ${ }^{2}$ especially in the case of isolated anomalies. In 2002, Argentina passed National Act no. 25630 to arrange the mandatory addition of
FA to wheat flour. ${ }^{3}$ The concentration of FA has been established at $2.2 \mathrm{mg}$ per kilogram of flour, similar to what is indicated in other countries. ${ }^{4}$ Folic acid fortification (FAF) was first implemented late in 2003. It has been estimated that the first newborn infants prenatally exposed to FA were born in the third quarter of 2004, and by 2005 most newborn infants had been exposed. Different studies demonstrated a significant reduction in NTD prevalence and mortality in the post-FAF period in Argentina. . $^{5-7}$

NTDs have a great emotional impact on families and also lead to a high monetary cost. Studies conducted in Chile, South Africa and the United States have demonstrated that FAF is a cost-effective intervention. . $^{8-10}$

The objective of this study is to describe the prevalence of NTDs in Argentina and estimate the number of cases averted in the 2005-2013 period, following flour fortification with folic acid.

\section{MATERIAL AND METHODS}

This is a descriptive, ecological, cross-sectional study. The material was obtained from the National Registry of Congenital Anomalies (Registro Nacional de Anomalias Congénitas, RENAC) and the LatinAmerican Collaborative Study of Congenital Malformations (Estudio Colaborativo Latinoamericano de Malformaciones Congénitas, ECLAMC). The ECLAMC is a registry of major structural CAs that has been in force since 1967 as a non-governmental network of hospitals from different South American countries. Before the RENAC was created, the ECLAMC was the only source of information 
regarding the prevalence of CAs in Argentina; ${ }^{11}$ therefore, the information reported by this system was used in this study as baseline data (pre-FAF period).

The RENAC is a CA surveillance system dependent on the Ministry of Health of Argentina. ${ }^{12} \mathrm{Up}$ to 2013 , it was made up of 122 public hospitals and 11 private maternity centers from across all 24 Argentine jurisdictions, and had covered $65 \%$ of births occurred in the public subsector and $38 \%$ of all births occurred in Argentina. The RENAC receives reports on newborn infants born with major structural CAs, whether external or internal, identified from birth until hospital discharge and detected during physical examination or using supplementary tests, interventions or an autopsy. All live newborn infants and stillbirths with a birth weight of $500 \mathrm{~g}$ or more are included. This study included the RENAC's data for the November 2009-December 2013 period regarding anencephaly (Q00), spina bifida (Q05), and encephalocele (Q01).

Based on the RENAC's data, the prevalence at birth of isolated cases of spina bifida, anencephaly and encephalocele were estimated for the period between November $1^{\text {st }}, 2009$ and December 31 $1^{\text {st }}$, 2013. Such estimation was the result of the ratio between the number of cases with these CAs and the total number of births, expressed per 10000 births. The estimated prevalences were compared to those reported by the ECLAMC for the pre-FAF period (2002-2004). ${ }^{5}$ For each comparison, the prevalence ratio (PR) and 95\% confidence intervals (CIs) as per Poisson's regression were estimated.

Only isolated cases were used to compare both periods: pre-FAF and post-FAF. Based on estimated prevalences for the pre-FAF and postFAF periods and considering the total number of births reported as per Argentina's vital statistics data for the 2005-2013 period, the number of cases averted in Argentina in this 9-year-period was calculated.

\section{RESULTS}

Between November $1^{\text {st }}, 2009$ and December $31^{\text {st }}$, 2013, the RENAC assessed 703325 births and reported 11373 cases with major CAs, which account for a prevalence of $1.62 \%$ (95\% CI: $1.59 \%-1.65 \%)$. Out of all reported cases, $517 \mathrm{had}$ NTDs, which account for a prevalence of 7.4 per 10000 births (95\% CI: 6.7-8.0). Out of all NTD cases, 164 had anencephaly; 303, spina bifida; and 50, encephalocele; all were isolated cases. Their prevalence per 10000 births was 2.33 (95\% CI: 1.99-2.72), 4.34 (95\% CI: 3.86-4.85) and 0.73 (95\% CI: 0.54-0.95), respectively. Compared to the ECLAMC's data for the pre-FAF period, a significant reduction was observed for the three types of defect. Anencephaly and encephalocele decreased by $66 \%$, and their PRs were 0.34 (95\% CI: 0.27-0.42) and 0.34 (95\% CI: 0.23-0.52), respectively, while spina bifida decreased by $47 \%$, with a PR of 0.53 (95\% CI: 0.44-0.64) (Table 1).

Considering that 6663150 infants were born in Argentina in the nine-year period from 2005 to 2013 and the prevalences for the pre-FAF and post-FAF periods, it was estimated that 11461 cases of any of these three types of NTD would have occurred with no FAF, while it was estimated that, with FAF, the number of cases added up to 4931 . The estimated number of cases averted in nine years was 6530, which would account for an annual primary prevention of 726 newborn infants with NTDs (Table 2).

TABLE 1.Prevalences and prevalence ratios of isolated neural tube defects in the pre-fortification and post-fortification periods

\begin{tabular}{|c|c|c|c|}
\hline & \multicolumn{2}{|c|}{ Prevalence $x 10000(95 \%$ CI $)$} & \multirow{2}{*}{$\begin{array}{c}\text { Prevalence } \\
\text { ratio } \\
(95 \% \mathrm{CI})\end{array}$} \\
\hline & $\begin{array}{l}\text { Pre-fortification period* } \\
\text { (ECLAMC, 2002-2004) }\end{array}$ & $\begin{array}{l}\text { Post-fortification period } \\
\text { (RENAC, 2009-2013) }\end{array}$ & \\
\hline Anencephaly & $6.92(5.80-8.20)$ & $2.33(1.99-2.72)$ & $0.34(0.27-0.42)$ \\
\hline Spina bifida & $8.16(6.94-9.54)$ & $4.34(3.86-4.85)$ & $0.53(0.44-0.64)$ \\
\hline Encephalocele & $2.12(1.52-2.87)$ & $0.73(0.54-0.95)$ & $0.34(0.23-0.52)$ \\
\hline
\end{tabular}

* López-Camelo JS, Castilla EE, Orioli IM. Folic acid flour fortification: impact on the frequencies of 52 congenital anomaly types in three South American countries. Am J Med Genet A 2010;152A(10):2444-2458.

RENAC: National Registry of Congenital Anomalies; ECLAMC: Latin-American Collaborative Study of Congenital Malformations. 


\section{DISCUSSION}

When comparing the prevalence observed by the RENAC in the post-FAF period to that reported by the ECLAMC for Argentina in the pre-FAF period, anencephaly and encephalocele decreased by $66 \%$, and spina bifida, by $47 \%$, which were significant reductions. In previous studies, spina bifida showed a higher reduction following FAF when compared to other NTDs; in this study, anencephaly and encephalocele showed greater reductions. Such reduction in encephalocele may be related to the lower number of cases, which results in a greater prevalence variation. The large reduction in the number of anencephaly cases may be related to an increase in antenatal diagnosis and pregnancy termination over the past years. Although pregnancy termination in Argentina is illegal, it is a widespread practice. ${ }^{13}$ Given that the RENAC does not record pregnancy terminations, an improved antenatal diagnosis of CAs that are easily detectable through ultrasonography, such as anencephaly, and subsequent pregnancy termination may be the cause of a higher reduction in the prevalence of anencephaly when compared to that of spina bifida, unlike what has been observed in other studies.

The estimated number of cases averted was higher for anencephaly, followed by spina bifida; encephalocele showed the lowest difference given that the prevalence of this defect was smaller. Although no cost-effectiveness studies have been conducted in Argentina, this study demonstrates the effectiveness of the FAF intervention by estimating the potential number of cases averted between 2005 and 2013.

The reduced prevalence observed in our study is lower than that observed in Chile ${ }^{5}$ and Costa Rica, ${ }^{14}$ but higher than that seen in Brazil. ${ }^{5}$ Such variation may be due to the effectiveness of different fortification strategies: variations in dose, in selected basic foods, and in the FAF period that was assessed. Variations in these countries' ethnic composition may be the result of a differential response to FAF. ${ }^{15}$

Our study has some limitations. Given that this is an ecological study, it is not possible to prove the causal chain between the intake of fortified foods and the reduction in the prevalence of NTDs. In addition, there may be other causative agents of such reduction not considered in this study, for example, changes in antenatal diagnosis followed by pregnancy termination, supplementation, diet, use of teratogenic drugs, etc.

Prevalences were compared using two different systems. Although the RENAC and the ECLAMC share similar case definitions and inclusion criteria, the ECLAMC covers a lower number of hospitals than the RENAC and includes tertiary care hospitals, which may increase the prevalence due to referral bias. In addition, prevalences estimated for the preFAF period are based on the small number of hospitals included in the ECLAMC, which may not be representative of the general population. On its side, the RENAC covers a high number of births occurred in the public subsector, but the private subsector is less represented, and there may be differences in prevalence between both subsectors.

\section{CONCLUSION}

Following the implementation of FAF in wheat flour in Argentina, a reduction in the prevalences of NTDs has been observed, which is consistent with observations made by other studies conducted in Argentina.

\section{REFERENCES}

1. Botto LD, Moore CA, Khoury MJ, Erickson JD. Neuraltube defects. N Engl J Med 1999;341(20):1509-19.

2. Prevention of neural tube defects: results of the Medical Research Council Vitamin Study. MRC Vitamin Study Research Group. Lancet 1991;338(8760):131-7.

3. Argentina. Ley Nacional $N^{\circ} 25630$ : Prevención de anemia y Defectos del Tubo Neural. (1 de agosto 2005). [Accessed

TABLE 2. Estimated number of averted cases of neural tube defects, 2005-2013 period, Argentina

\begin{tabular}{|c|c|c|c|c|c|}
\hline & & Anencephaly & Spina bifida & Encephalocele & Total \\
\hline \multirow{2}{*}{$\begin{array}{l}\text { Estimated number } \\
\text { of cases }\end{array}$} & Without fortification* & 4611 & 5437 & 1413 & 11461 \\
\hline & With fortification* & 1553 & 2892 & 486 & 4931 \\
\hline \multicolumn{2}{|c|}{ Number of averted cases } & 3058 & 2545 & 927 & 6530 \\
\hline
\end{tabular}

* Estimation based on 6663150 births occurred in Argentina in the 2005-2013 period (source: annual reports of the Statistics and Health Information Department [Dirección de Estadística e InformaciónenSalud], 2006-2014). 
on: July 1,2015]. Available at: http:/ / www. anmat.gov.ar/ Legislacion/Alimentos/Alimentos/Ley_25630.pdf.

4. Castillo-Lancellotti C, Tur JA, Uauy R. Impact of folic acid fortification of flour on neural tube defects: a systematic review. Public Health Nutr 2013;16(5):901-11.

5. López-Camelo JS, Castilla EE, Orioli IM. Folic acid flour fortification: impact on the frequencies of 52 congenital anomaly types in three South American countries. Am J Med Genet A 2010 152A(10):2444-58.

6. Calvo E, Biglieri A. Impacto de la fortificación con ácido fólico sobre el estado nutricional en mujeres y la prevalencia de defectos del tubo neural. Arch Argent Pediatr 2008;106(6):492-8.

7. Bronberg R,Alfaro E,ChavesE,AndradeA, etal.Mortalidad infantil por anencefalia en la Argentina: análisis espacial y temporal (1998-2007). Arch Argent Pediatr 2011;109(2):117-23.

8. Llanos A, Hertrampf E, Cortes F, Pardo A, et al. Costeffectiveness of a folic acid fortification program in Chile. Health Policy 2007;83(2-3):295-303.

9. Sayed AR, Bourne D, Pattinson R, Nixon J, Henderson B. Decline in the prevalence of neural tube defects following folic acid fortification and its cost-benefit in South Africa. Birth Defects Res A Clin Mol Teratol 2008;82(4):211-6.
10. Bentley TG, Weinstein MC, Willett WC, Kuntz KM. A costeffectiveness analysis of folic acid fortification policy in the United States. Public Health Nutr 2009;12(4):455-67.

11. Castilla EE, Orioli IM. ECLAMC: The Latin-American Collaborative Study of Congenital Malformations. Community Genet 2004;7(2):76-94.

12. Groisman B, Bidondo MP, Barbero P, Gili J, et al. RENAC: Registro Nacional de Anomalías Congénitas de Argentina. Arch Argent Pediatr 2013;111(6):484-94.

13. Mario S, Pantelides EA. Estimación de la magnitud del aborto inducido en la Argentina. En CEPAL. Notas de población. 2009;87:95-120. [Accessed on: May 8, 2015]. Available at: http://repositorio.cepal.org/bitstream/ handle/11362/37695/S0700736_es.pdf?sequence=1.

14. Barboza-Argüello M de L, Umaña-Solís LM, Azofeifa A, Valencia D, et al. Neural tube defects in Costa Rica, 1987-2012: origins and development of birth defect surveillance and folic acid fortification. Matern Child Health J 2015;19(3):583-90.

15. Williams LJ, Rasmussen SA, Flores A, Kirby RS, Edmonds LD. Decline in the prevalence of spina bifida and anencephaly by race/ ethnicity: 1995-2002. Pediatrics 2005;116(3):580-6. 